Document downloaded from:

http://hdl.handle.net/10251/120654

This paper must be cited as:

Nieto-Alemán, PA.; Roig Tierno, H.; Mas Verdú, F.; García Alvarez-Coque, JM. (2018). Multidimensional paths to regional poverty: a Fuzzy-set qualitative comparative analysis of Colombian departments. Journal of Human Development and Capabilities. 19(4):499-520. https://doi.org/10.1080/19452829.2018.1504760

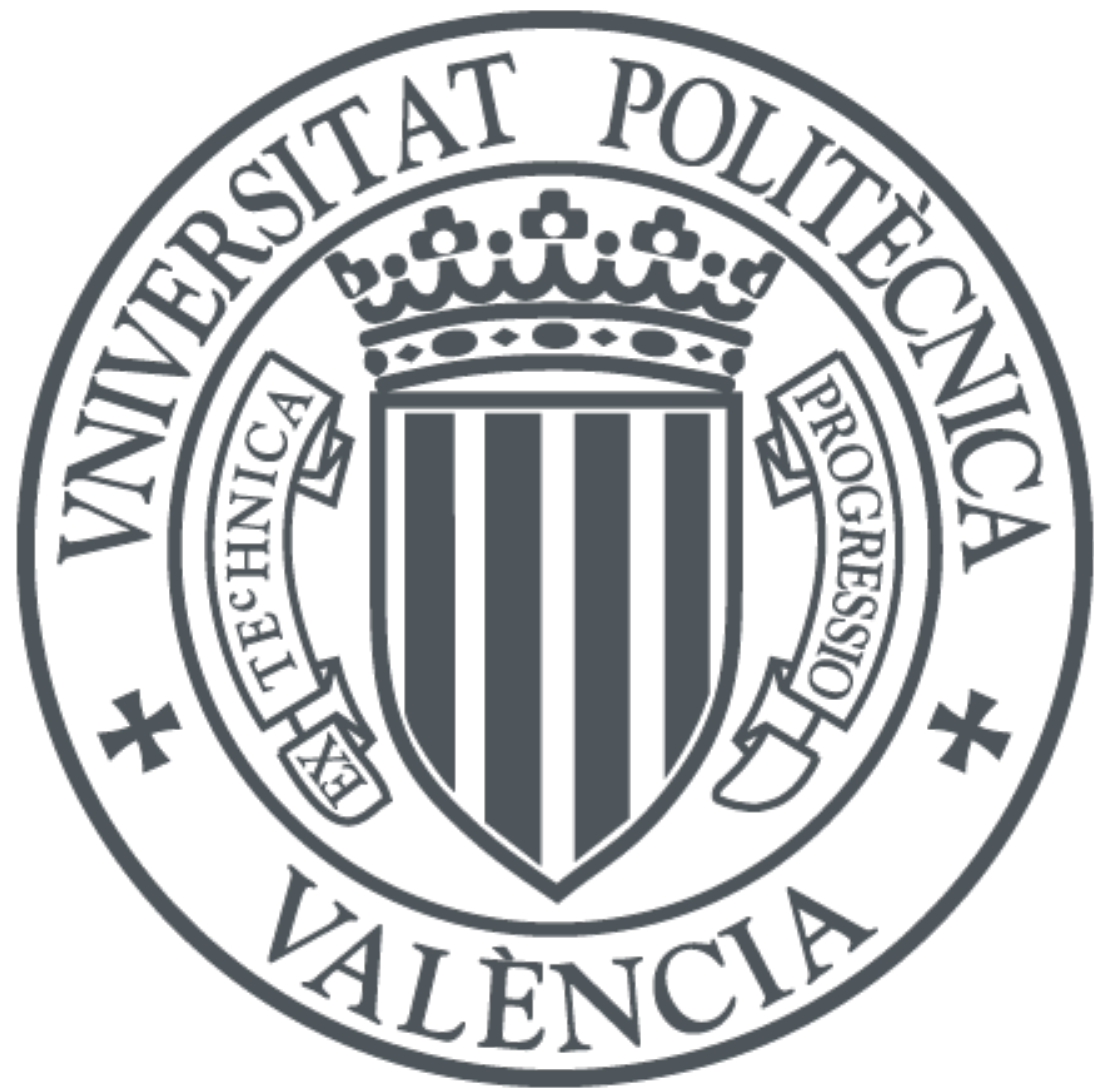

The final publication is available at

http://doi.org/ 10.1080/19452829.2018.1504760

Copyright Taylor \& Francis

Additional Information

This is an Author's Accepted Manuscript of an article published in Nieto-Alemán, Paula Andrea, Roig Tierno, Honorat, Mas Verdú, Francisco, García Alvarez-Coque, José María. (2018). Multidimensional paths to regional poverty: a Fuzzy-set qualitative comparative analysis of Colombian departments.Journal of Human Development and Capabilities, 19, 4, 499-520. DOI: 10.1080/19452829.2018.1504760, available online at: http://doi.org/ $10.1080 / 19452829.2018 .1504760$ 


\section{Multidimensional Paths to Regional Poverty: A Fuzzy-Set Qualitative Comparative Analysis of Colombian Departments}

This paper provides a simple, systemic, holistic assessment of regional conditions that lead to capability deprivation. Capability deprivation is measured at the regional level using the indicators of monetary poverty and life expectancy in Colombia. Fuzzy-set qualitative comparative analysis (fsQCA) is used to identify necessary or sufficient conditions for high and low deprivation in Colombian departments (regions). The multidimensional paths consist of combinations of economic conditions (GDP per capita and trade openness), social conditions (education) and institutional conditions (transparency and internal displacement). The observed interactions between conditions indicate that no single condition leads to regional poverty. Peace and transparent institutions are important conditions in most of the paths that lead to high or low capability or functioning indicators.

Keywords: multidimensional paths to poverty; monetary poverty; life expectancy; territorial approach; violence; qualitative comparative analysis; peace; institutions; Colombia

JEL subject classification codes: R110, I320, O5 


\section{Introduction}

In this paper, we adopt a multidimensional approach to examine the social, political and economic conditions in regions with high or low capability deprivation and poverty measured in terms of social indicators for those regions. The academic discussion of poverty covers different viewpoints in terms of the conceptualization and measurement of poverty (Sen 2001; Deaton 2010; Alkire and Santos 2013; Ele-Ojo Ataguba, Eme Ichoku, and Fonta 2013). However, poverty is not usually considered an outcome of the specific attributes of the region. It may therefore be of interest to inquire as to the attributes of regions where poverty is particularly low or high. The answer may be conditioned by the specific social, political and economic structure of those regions.

The method proposed in this paper can be used to evaluate policies according to their influence on certain outcomes measured in terms of regional social indicators. We selected two outcomes that relate to capability deprivation and that can typically be measured at the regional level. These are monetary poverty (MP) and life expectancy (LE). The proposed analytical framework stresses the distinction between means and ends that has been considered in studies that have adopted a capability approach. According to this approach, policies and other regional conditions can be evaluated according to their impact on people's capabilities (Alkire and Deneulin 2009).

To conduct our analysis, we used an alternative to standard regression methods, which fail to effectively capture possible combinations of relevant conditions because the isolated effect of a specific variable usually does not explain a given outcome. Instead, different sets of conditions define alternative pathways that may be necessary, sufficient or both for a given outcome to occur. In this study, the outcome was regional poverty reduction. Fuzzy-set qualitative comparative analysis (fsQCA) provided a suitable method to identify the causal conditions that lead to high or low levels of 
poverty in a given region. FsQCA enables identification of a set of conditions or attributes that together form alternative pathways or recipes that lead to a specific outcome (Collier 1993; Ragin 2008; Schneider and Wagemann 2010; Fiss 2011).

When selecting regional conditions, we considered the economic, political and social context of Colombia. In this paper, we underline the role of institutional variables and peace as factors of regional poverty. The history of Colombia's departments has been marked by violence. Aspects such as governance, social policy, regional conflict, the abundance or scarcity of resources, and macroeconomic strategy can help us understand alternative pathways to prosperity or to capability deprivation. The importance of the combination of economic, social and institutional dimensions in the regional analysis of poverty justifies this comparative analysis of Colombian departments.

In this study, the economic dimension comprised GDP per capita and the degree of trade openness (Charlton and Stiglitz 2004; Rodrik 2005; Glick and Taylor 2010). The social dimension was measured using coverage of education (Sen 2001). The institutional dimension comprised the transparency and stability of public institutions (Powell and DiMaggio 1991; Akanbi 2014). The absence of effective institutions contributes to explaining regional inequalities. Ele-Ojo Ataguba, Eme Ichoku, and Fonta (2013) highlight the role of institutions amongst the factors that can potentially reduce regional poverty. Several studies have documented the impact of domestic conflict on regional poverty (Piazza 2011; Hegre and Nygård 2014). Using fsQCA, we can determine which of these conditions create paths to high or low capability deprivation. FsQCA provides a useful tool for policy analysis when data are scarce and the sample of regions is small. 
This paper is structured as follows: Section 2 begins with a general description of the indicators used to measure regional poverty in Colombia. Section 3 establishes the conceptual background and explains the selection of conditions that form pathways to or from regional poverty. The research questions explored in this study are also formulated. Section 4 describes the fsQCA method and introduces the data used in the study. Sections 5 and 6 discuss the results and present the conclusions.

\section{Regional Poverty Indicators in Colombia}

According to the World Bank's basic needs classification, which is based on gross national income (GNI), Colombia is an upper-middle-income country. Research has shown that regional convergence in Colombia exists in key social variables but not in GDP per capita (Royuela and Garcia 2015). This finding suggests that the set of regional conditions that potentially determine poverty should be broadened to consider more than just GDP per capita.

Colombia regularly publishes indicators of MP. The UNDP (2015) report shows that, in Colombia, the incidence of MP declined from 49.7\% in 2002 to $32.7 \%$ in 2012 and the incidence of extreme MP decreased from $17.7 \%$ in 2002 to $10.4 \%$ in 2012. However, whilst the UNDP report acknowledges these declining poverty rates, it warns that progress is too slow. The UNDP report also highlights how extreme poverty in Colombia is still concentrated in rural areas, where one in two people are poor, rather than urban areas, where one in four are poor. In addition, there are huge disparities across departments; regional MP rates range from $11 \%$ to $60 \%$, with MP rates greater than 50\% in Cauca, Guajira, Magdalena, Chocó, Córdoba, Nariño, and Sucre.

In the context of regional analysis, the availability of statistics for Colombia's departments constrains the choice of indicators of capabilities or functioning for a cross- 
sectional approach. This study examined sources of regional disparities. In addition to using income-based MP, we chose another relevant indicator of well-being achievement, namely LE, which has been widely used as a human development indicator (Strezov, Evans, and Evans 2017). LE figures in Colombia also vary. For the period 2001 to 2015, LE ranged from $69.30 \%$ in Chocó to 78.01\% in Bogotá.

Multidimensional poverty indicators, including different aggregated capabilities or functionings, are also published for Colombia, but not at the department level and only for large areas (Caribe, Oriental, Pacifica, Bogotá, Valle del Cauca, and Antioquia). Multidimensional poverty varies significantly amongst large departments (Angulo, Díaz, and Pardo 2016). In any case, a direct correlation between income-based indicators and other indicators of functioning or capabilities cannot be expected. This specificity of capability or functioning indicators led us to carry out two separate analyses using fsQCA: one for MP and one for LE.

\section{Conceptual Framework}

Mainstream poverty research has generally failed to address structural and relational factors that cause poverty (Harriss 2007). An acceptance that human development is an end in itself (Streeten 1994) raises the question of which regional institutional, economic and social conditions, which may also be ends, can alleviate regional poverty. Empirical work and poverty studies have cited numerous approaches to studying linkages with development and regional growth (Bastiaensen, De Herdt, and D’Exelle 2005; Belhadj and Liman 2012; Neff 2013). Many studies have measured poverty instead of understanding what feeds this complex phenomenon. Likewise, few studies have explored the linkages amongst the factors that affect regional poverty 
(Mwangi and Markelova 2009; Belhadj 2011; Neff 2013), at least from a regional perspective such as the one adopted in this paper.

Regions are endowed with attributes. These include institutional, educational and economic conditions. This paper provides a method to identify pathways to or from regional poverty. Thus, the primary goal of our research strategy was to identify regional attributes whose presence or absence in each region could be monitored. According to Misangyi et al. (2017), complex causality has three dimensions. The first, conjunction, means that the outcome is the result of interdependency amongst several conditions. The second, equifinality, means that there is more than one path to a specific outcome. The third, asymmetry, implies that conditions "found to be causally related in one configuration may be unrelated or even inversely related in another" (Meyer, Tsui, and Hinings 1993, 1178). Therefore, fsQCA was suitable for studying our research questions. The fsQCA method that is described in the next section was applied to establish logical rules about how to combine the identified attributes. In a fuzzy framework, such rules define alternative pathways or recipes that are necessary or sufficient for the presence or absence of capability deprivation.

Many scholars adopting a capability approach have reported that MP is not enough to measure well-being (Kolm 1977; Atkinson and Bourguignon 1982; Tsui 1995; Maasoumu 1986; Sen 1999). Income-based poverty measures focus on the deprivation of only one dimension of poverty (Anand and Sen 1997). Some authors recommend a multidimensional approach to measure poverty through a series of indicators that reflect the well-being of individuals (Atkinson and Bourguignon 1982; Cerioli and Zani 1990; Smeeding et al. 1993; Betti, Gagliardi, Lemmi, and Verma 2012). Bourguignon and Chakravastry (2003) argue that poverty multidimensionality arises because policymakers expect to define a poverty limit for each individual 
attribute (health, education, income, etc.). However, because of the scarcity of regional indicators, we used two unidimensional indicators of deprivation: MP and LE. Our goal was to identify the attributes that, when combined in different ways, are associated with high or low levels of capability deprivation.

\subsection{Transparent Institutions}

We were interested in determining the presence or absence of peace and transparent institutions, as well as other social and economic attributes, as conditions for regional poverty. Institutions are shaped by the dominant traits in society. They are holistic concepts that individuals construct over time. Institutions can be considered as the set of rules that articulate political interactions between individuals and social groups (North 1993, 13). Their influence on poverty and inequality is well established.

Amin (1999, 367-368) considers that the economy emerges as a composition of collective influences which shapes individual action and as a diversified and pathdependent entity moulded by inherited cultural and socio-institutional influences. In this sense, institutions are conceived as stabilizing entities that play a key role in economic development and in the propagation or elimination of poverty. Institutions are not only the bedrock of economic activity but also the means to resolve conflicts and economic contradictions (March and Olsen 1989; Thelen 2004). Control of corruption, combined with a stable political system and effective government, could lead to economic growth, which in turn could reduce conflicts over income distribution. This control and stability could have implications for poverty (Tebaldi and Mohan 2010).

Unequal regional development is partly due to the actions of institutions (Massey 1985; Krugman 1997; World Bank 2009). Institutions determine economic 
growth and influence the distribution of wealth (North 1991; Acemoglu and Robinson 2012). Institutions are thus a pillar of regional development.

Transparency International reports that corruption control in Colombia is still weak (Transparencia por Colombia 2015). The control of corruption reflects the perception of the extent to which elites and private interests capture the public power. The Colombian people have little confidence in their police, rules or justice and a lack respect for property rights. Our hypothesis is that transparent, decentralized, responsible institutions determine the economic and political outcomes of the region. Their weakness is a factor of poverty.

Proposition 1a: A lack of transparency in public institutions leads to high rates of regional capability deprivation.

\subsection{Peace}

Armed conflicts are usually accompanied by fragile social conditions and weak conditions of production (Carusso and Schneider 2011; Bretthauer 2014). Bara (2014) used qualitative comparative analysis (QCA) to identify a number of explanatory factors that were closely related to the onset of 78 ethnic conflicts between 1990 and 2009. The conclusion was that the presence of instability or conflict in a neighbouring state could lead to rebellion against the government and its representation in laws and authority. Hegre, Østby, and Raleigh (2009) suggested that inequality and discrimination were strongly associated with poverty and war in the case of Liberia. A lack of credibility and security in a given region increases the risk of poverty amongst the population of that region and highlights the vulnerability of institutions and society in general (Justino 2009; Ali 2010). 
Violence has dominated Colombia's recent history, highlighting the fragility of institutions where individual interests prevail over the common good. Certain armed groups did not begin to demobilize until the second half of the 1980s. However, drug cartels became more active, and the Colombian people were plunged into an uncontrollable war, which only waned at the beginning of the $21^{\text {st }}$ century (Banks and Sokolowski 2009).

According to Bara (2014) and Flores (2014), the armed conflict in Colombia (guerrillas, paramilitaries and drug trafficking) can be directly linked to the increase in poverty. Flores (2014) highlights the lack of credibility in the way the Colombian state allocated land. The most vulnerable farmers were marginalized by the forceful removal of their land, which in many cases has caused internal displacement.

Camacho and Rodríguez (2012) proposed a model to explain the relationship between armed conflict and managing a business in Colombia. The authors report a $5.2 \%$ probability that a company will leave a city in a situation of war. This percentage is higher if the company is young and lacks capital. Although measures have been taken to combat crime, insurgency and drug trafficking, these problems persist in Colombia, despite progress made during the ongoing peace process.

Proposition 1b: Regions with high levels of displacement have high regional capability deprivation.

\subsection{Income and Trade}

Regional economic conditions appear to be a standard consideration for analysing the presence or absence of poverty. Solow (1957) and Barro (1991) emphasize the links between sustained economic growth and improvements in the quality of life of a country's inhabitants. Cervantes-Godoy and Dewbre (2010) 
performed cross-sectional regression analysis and identified economic growth as a relevant component of poverty reduction. Housseima and Rejeb (2012) modelled how growth, inequality and other explanatory factors interacted with poverty in 52 developing countries between 1990 and 2005. Their findings indicate that growth is not enough to reduce poverty, a finding reflected by the empirical literature on growth and poverty in Latin America (Iniguez-Montiel 2014). Growth appears to be a necessary but not sufficient condition for poverty reduction. It must be accompanied by other factors such as policies to reduce inequality. Blomberg and Hess (2002) and Piazza (2011) highlight the interdependencies between economic and social conditions and conflicts to explain the pitfalls of poverty. Economic recovery is also considered crucial for a return to a peaceful political situation (Flores and Nooruddin 2008).

Trade is another driver of development (Charlton and Stiglitz 2004). Hegre, Oneal, and Russett (2010) showed that trade reduces the risk of conflict between states. Glick and Taylor (2010) also underline the relationship between market disruption and peace. However, evidence of the connection between trade openness and economic growth is far from conclusive (Rodrik 2006). Under the right political and economic conditions, trade could boost social welfare, although this process depends on other factors such as adequate public and private infrastructure (Soriano and Garrido 2015). Rodrik $(2005,8)$ focused on the impossibility of predetermining "what a country should produce," suggesting that countries "should focus on production that maximizes growth." What leads to the prosperity of a country or region is not only a comparative advantage but also the ability to invest resources in new areas. Differences in the capabilities of regions derived from their cultural identities and idiosyncrasies may also limit the translation of economic growth and trade into welfare (Fosu 2011). 
In this paper, we test whether regional pathways to low capability deprivation include high per capita income or high trade openness. Of course, these conditions must be combined with other institutional and social attributes, so it is plausible that a single condition is not sufficient to achieve the desired outcome.

Proposition 2a: Regions with the lowest per capita income have the highest regional capability deprivation.

Proposition 2b: A lack of regional openness leads to high regional capability deprivation.

\subsection{Education}

Our multidimensional set of conditions that lead to poverty spans the social dimension. According to Sen $(2001,36)$, "an improvement in education and health contributes to higher incomes" and, therefore, improves living standards. According to the capabilities approach, political and economic freedoms include the individual's right to acquire the skills necessary to lead the life a person deserves. It is perceived that education allows people to work towards their personal ambitions (Müller 2011). Education can provide a way out of the poverty trap by enabling access to higher income and meeting basic needs (Awan et al. 2011). Low levels of education are closely linked to high levels of poverty. This link is accentuated in developing countries (Iniguez-Montiel 2014).

Empirical evidence also suggests that people's level of education can exert a direct influence on conflict (Lee 2011; Benmelech, Berrebi, and Klor 2012). Individuals without a well-defined path of progress are more likely to participate in armed conflicts than are individuals in more favourable perspectives (Caruso and Schneider 2011; Bara 2014). Education is a plausible driver of poverty reduction that must be combined with 
other institutional and economic conditions. Accordingly, multidimensional paths to low regional MP or high regional LE may include the coverage of education. This information is available at the regional level for Colombia.

Proposition 3: Regions with lower levels of education/human capital have higher regional capability deprivation.

\section{Method: fsQCA}

Complexity can be explored for small samples (in our case, Colombian departments) using a method that evaluates the combined effect of a set of conditions. In this study, fsQCA provided a useful method for identifying different configurations of conditions that are present in departments with high poverty rates. In addition, the combination of conditions that determine regional capability deprivation may change depending on the capability or functionality that is chosen. The chosen method enabled identification of the recipes that are valid for one capability (i.e. MP or LE) and that are not necessarily the same for other capabilities.

FsQCA is a variant of the QCA method, which is based on the categorization of cases depending on whether certain attributes are present or absent. Consistency is then explored in relation to the presence or absence of an outcome of interest (Rihoux and Ragin 2009; Vis 2012). QCA uses set theory to define combinations of the presence or absence of certain attributes. Through a systematic comparison of cases, QCA can be used to determine whether the presence or absence of an attribute is necessary or sufficient for the presence or absence of a given outcome. This approach differs from traditional statistical methods, which are based on estimating marginal intensities of individual elements (Ragin and Fiss 2008) rather than establishing case categories in which the presence of specific attributes can be observed individually or jointly. 
QCA analyses the relationships between conditions and a given outcome of interest in terms of the necessity or sufficiency of these conditions. A condition is necessary if it must be present for the outcome to occur. In other words, the outcome cannot occur in the absence of that condition. A condition is sufficient if the presence of that condition by itself determines the outcome. However, that condition need not be present for the outcome to occur" (Ragin 2008).

QCA has several variants, all based on Boolean logic. This family of methods is based on two key concepts: conditions, which explain a given outcome, and that outcome itself. Crisp-set QCA (csQCA) categorizes conditions depending on whether they are "completely in" (value 1) or "completely out" (value 0 ) of a set. To overcome the limitations of this dichotomization, Ragin developed fsQCA, which does not require cases to belong to either of these two categories but instead allows the scaling of explanatory factors or conditions in the interval from 0 to 1 . Different cut-off points in this interval are defined through calibration of the conditions and the outcome. In our study, fsQCA was the most suitable variant of QCA because it enabled the use of continuous scales at the regional level. The fsQCA method allowed us to understand the patterns or associated pathways that validate the existence of the aforementioned relationships, according to the level of poverty, based on quantitative and qualitative information (Schneider and Wagemann 2010).

\subsection{Data and Design of Fuzzy Sets}

Five conditions, which could either be present or absent, and two outcomes were considered in this fsQCA study of regional poverty in Colombia. Two conditions referred to institutions (transparency and displacement), one to education and two to economic performance (GDP per capita and trade openness). Two outcomes were 
selected in this research to reflect high (or low) capability deprivation. These were MP and LE.

MP was measured using the regional rate of monetary poverty, which indicates the percentage of people living under the poverty line (DANE 2015d). LE is calculated at the departmental (regional) level and is published by DANE (2018). The construction of different combinations and types of relationships determines the relevant combination of attributes present in Colombian departments with high or low deprivation. Table 1 lists the sources and describes the variables used to characterize the departments.

Because we were interested in regional poverty, we considered the division of the country into administrative departments. The Constitution (Constitution of Colombia 1991) grants each department autonomy to plan and promote economic and social development within the department. The department-wide transparency index was used to investigate the quality of institutions. Forced displacement figures reflect the key role of institutions as stabilizers of entities and their responsibility for ensuring civilian security. In Colombia, a displaced person is defined as

a person who has been forced to migrate within the national territory, abandoning that person's place of residence or usual economic activities, because that person's life, physical integrity, safety or personal freedoms have been violated or are directly threatened by violations of international humanitarian law or serious and manifest violations of international standards of human rights during the internal armed conflict. (Article 60, Paragraph 2, Law 1448 of 2011)

According to the 2012 displacement figures for Colombia, approximately $10 \%$ of the national population was considered a victim of forced displacement (Unidad para 
la Atención y Reparación Integral de las Víctimas 2013, 11). This is one of the variables used in this study to indicate the contribution of institutions to peace and poverty reduction.

The economic conditions considered in this study were GDP per capita and regional trade openness. GDP per capita was used to proxy regional economic performance. The institutional conditions were forced displacement and the transparency index. Finally, the social conditions were enrolment in secondary education.

[Table 1 near here]

As indicated above, the analysis was based on a Boolean comparison of cases in terms of the presence or absence of certain conditions. Items can have partial membership to a fuzzy set. Consequently, fsQCA requires calibration of the conditions and the outcomes to define membership to the set. The results of the calibration are shown in the Appendix. Ragin (2008) proposes three thresholds for the direct calibration of conditions. He defines the thresholds as "full presence" in the set (0.95), "full absence" from the set (0.05), and the point of maximum ambiguity (0.5). In this study, there was no prior knowledge, so we used the $90^{\text {th }}$ and $10^{\text {th }}$ percentiles as cut-offs to determine full presence and full absence, respectively, and the median to establish the point of maximum ambiguity (Misangyi and Acharya 2014).

\section{Findings and Discussion}

\subsection{Necessary Conditions}


For a condition to be considered necessary in fsQCA, consistency must be at least 0.90 (Ragin 2008; Schneider, Schulze-Bentrop, and Paunescu 2010). The absence of high GDP per capita in Colombian departments has a consistency of slightly more than 0.85 (Table 2), suggesting that such a condition plays a relevant but not determinant role in the presence of high MP. The same table indicates that no condition is essential for the presence of high MP rates in the analysed departments. Three conditions are also consistently relevant but not necessary for the absence of MP (consistency less than 0.9). These conditions are presence of high GDP per capita $($ consistency $=0.80)$, institutional transparency $($ consistency $=0.78)$ and a lack of forced displacement $($ consistency $=0.76)$. These results confirm that no condition per se is limiting for the region to have high or low MP rates, although the consistency scores indicate some features that might form part of the pathways to the outcome. Similarly, no condition was found to be necessary for high or low LE. Although the absence of forced displacement has a relatively high consistency score, this score is less than $0.83 .^{1}$

[Table 2 near here]

\subsection{Sufficient Conditions}

Two analyses of sufficient conditions were conducted. First, we sought pathways or recipes that lead to the presence of capability deprivation in Colombian departments. Second, we sought configurations that lead to the absence of capability deprivation. Table 3 shows four pathways to high regional MP and three pathways to

\footnotetext{
${ }^{1}$ Consistency and coverage indicators for LE are available upon request.
} 
low LE. Table 4 also shows two pathways to low regional MP and three pathways to high LE.

The analysis technique enabled classification of the Colombian departments into several groups. Each department was grouped according to the frequency with which the paths leading to high or low MP align with the characteristics of that department (Figure 1). Thus, if a department belongs to multiple paths that lead to positive or negative outcomes, this may reflect greater political stability in achieving a positive outcome or, conversely, greater political difficulty in escaping from a negative outcome.

[Figure 1 near here]

\subsubsection{High Deprivation}

We developed a general model comprising all possible configurations that explain high MP rates in Colombian departments. The configurations include the presence or absence of transparency, displacement, GDP per capita, trade openness and education. The theory indicates that the absence of transparency (Proposition 1b), GDP per capita (Proposition 2a), trade openness (Proposition 2b), and education (Proposition 3) and the presence of displacement (Proposition 1a) lead to high MP. Because all conditions seem to matter, the question is whether we can define a simplified configuration that is consistent with the outcome of high poverty rates.

FsQCA simplified the analysis by highlighting the configurations that lead to the outcome. Table 3 presents the configurations selected after applying a cut-off of 0.9 to the truth table. The complete model has a consistency score of 0.9 , meaning that it is robust to interpretation (Fiss 2011). 
[Table 3 near here]

As expected, no single pattern is applicable to all departments with high MP (see the first four columns in Table 3). In general, economic and institutional conditions are important for determining MP in Colombian departments because they are present in all four configurations leading to high MP. Low GDP per capita is also important and is present in these four configurations. However, low GDP per capita per se is not limiting. It must be complemented by other conditions, primarily institutional, to create a sufficient pathway to high MP rates. In three of the four configurations for high MP, the presence of internal displacement is a relevant condition. Figure 2 offers a simplified illustration of the logical structure of the configurations for high MP.

[Figure 2 near here]

Configurations 1 and 2 are logical configurations for high regional poverty rates: O GDP per capita * $\mathbf{O}$ transparency * $(\mathbf{O}$ openness + $\mathbf{1}$ displacement $)$. Here, “ $\mathbf{O}$ " denotes absence of the condition, " $\mathbf{\square}$ " presence of the condition, and "+" denotes the logical operator "OR". Thus, departments with a low GDP per capita, a lack of institutional transparency and a lack of openness or forced displacement have the highest MP rates. Note here that low GDP per capita by itself is not sufficient for high poverty. Configurations 3 and 4 represent two other routes to poverty: GDP* displacement $*(\mathbf{O}$ opening $+\mathbf{O}$ education $)$. These paths show that departments with low GDP per capita, forced displacement and a lack of openness or a lack of education have high MP rates. 
Thus, four paths can be defined for departments with high MP. They correspond to groups of departments shown in the upper part of Figure 3(a). The data show that 22 Colombian departments have high MP rates and that 13 have low MP rates. Figure 3(a) and 3(b) also shows maps of the studied departments corresponding to pathways that were identified during the fsQCA. The departments were grouped by the median value to differentiate between the presence and the absence of a given attribute.

Almost all departments with high MP rates are represented by configurations MP1 and MP2. The exceptions are Córdoba, Nariño, and Norte de Santander, which are represented by configurations MP3 and MP4 and which have low GDP per capita and high forced displacement, in addition to a lack of openness (MP3) and education (MP4). Most departments with high MP rates are represented by more than one sufficient configuration, reflecting the fact that poverty must be addressed using complex or multidimensional solutions. The most problematic departments are Chocó, which is represented by the four selected configurations, and Cauca, Caquetá, and Tolima, which are represented by three of the four. All these departments have forced displacement and low GDP per capita. In the year 2010, the percentage of forced displacement in departments with high poverty rates was $56.1 \%$ of the national total, although these 11 departments accounted for only $14.6 \%$ of Colombia's total GDP. With the exception of Nariño, Norte de Santander, and Córdoba, all departments with high poverty rates had low levels of institutional transparency. This finding does not mean that the situation is easier for departments represented by only one of the four configurations, but it does mean that the problematic pathways are more limited. Huila, Córdoba, Sucre, and Nariño are represented by only one configuration (Figure 1). This configuration includes a high presence of internal displacement, suggesting that peace in these departments is critical for combating poverty. 
Several configurations are associated with low LE, but only one configuration overlaps with a configuration for low MP. For both high MP and low LE, configurations MP3 and LE1 highlight the relevance of forced displacement, in addition to the absence of adequate economic conditions. Configuration MP1 is similar to configuration LE2 in that both include the absence of transparency and the lack of adequate economic conditions. However, configuration LE3 does not need low GDP per capita to lead to low LE. In configuration LE3, other conditions such as education, transparency and trade openness are absent, and displacement is present. In other words, departments may fail to support LE when some social and institutional conditions fail, not necessarily where there is low GDP per capita (Figure 3(a)).

[Figure 3(a) near here]

In summary, several multidimensional paths to poverty were identified. Policies can be implemented to break some of the limiting conditions of the most troublesome combinations.

\subsubsection{Low Deprivation}

In addition to identifying configurations that are consistent with high regional deprivation, the fsQCA method also allowed us to identify conditions for successful departments. These departments are characterized by low MP or high LE. In theory, the conditions that lead to these outcomes should be the absence of displacement (Proposition 1b) and the presence of high transparency (Proposition 1a), high GDP per capita (Proposition 2a), trade openness (Proposition 2b) and education (Proposition 3). 
The first two columns in Table 4 and the bottom of Figure 3 show two configurations that have consistency scores that surpass the consistency threshold and that are sufficient for low regional MP. Here, the pattern of pathways to success (i.e. achieving a desirable outcome) is much simpler than the pattern of pathways to failure. One clear configuration leading to low regional MP is the presence of high GDP per capita (MP4). This finding suggests that whilst low economic growth may not be sufficient to determine failure (see the discussion on pathways to high poverty), fast growth appears to be sufficient to determine success. However, high GDP per capita is not the only path to low MP. Regardless of GDP per capita, configuration MP5 also leads to low MP. Notably, MP5 comprises only institutional variables.

Configuration MP4 is applicable to all departments with low MP, except Quindío and Caldas, which are represented by MP5. Configuration MP4 indicates the importance of institutional transparency and low levels of forced displacement for low MP.

The departments represented by MP4 account for 79\% of Colombia's total GDP. Five of these departments (Antioquia, Bogotá, Cundinamarca, Santander, and Valle del Cauca) account for $62 \%$ of Colombia's total GDP. These departments host most of Colombia's manufacturing, generating clusters that are conducive to development. However, the analysis of successful departments seems to indicate that departments with high-quality institutions and low displacement (i.e. peace) can achieve the desired outcome, regardless of their GDP per capita. Thus, Boyacá, Cundinamarca, Risaralda, Atlántico, Santander, and Valle del Cauca, which are well-performing departments in terms of income, also have institutional and personal safety attributes that form a sufficient path to low MP (Figure 1). Quindío and Caldas, both of which are located in the Coffee Belt (Eje Cafetero), exemplify departments with high institutional quality. 
Although they have relatively low incomes, they have low rates of regional poverty. Institutions and peace are thus critical for combating poverty.

[Table 4 near here]

[Figure 3b near here]

When combined with transparent institutions, which appear in configuration LE5, suitable macroeconomic conditions also form part of configuration LE6, which leads to high LE. Absence of forced displacement is part of configurations LE4 and LE5, regardless of GDP per capita. Education is present in configuration LE4.

All the propositions stated earlier are corroborated by the analysis. However, no condition is a necessary or unique antecedent of achieving or failing to achieve the desired outcome. Combinations of some of these conditions form sufficient paths to low or high values of capability deprivation indicators. However, we identified no single pattern that indicates whether a department has high or low poverty. In most paths, besides economic growth, institutional factors play a prominent role in achieving a positive outcome.

\section{Conclusions}

In this study, we used fsQCA to identify configurations of economic, social and institutional conditions linked to poverty in 24 Colombian departments. Interactions amongst these conditions illustrate the complexity of the phenomenon and indicate that no single condition is essential for the presence or absence of high or low MP or LE in all Colombian departments. Whilst low GDP per capita is present in all sufficient paths 
for high MP and most sufficient paths for low LE, this attribute is usually accompanied by other economic, social or institutional conditions. Forced displacement and a lack of institutional transparency are part of several sufficient configurations for high regional MP or low regional LE.

High GDP per capita is not included in some of the pathways to desirable outcomes. One configuration that determines low MP and two configurations that determine high LE primarily consist of institutional variables, regardless of GDP. This finding stresses the role of transparent institutions and personal safety in alleviating deprivation. These two factors were found to be critical in some departments.

Colombia is facing a historic challenge. In 2012, the Colombian government initiated a peace process with the FARC-EP, which was scheduled to conclude with the signing of an agreement between the parties in the first half of 2016. Negotiations have followed a mutually agreed upon agenda to address Colombia's problems in the postconflict period. This study's findings are relevant to the current process and support the urgent need to improve governance and consolidate peace. Our study provides further evidence that peace and governance are not individually necessary but together could offer a path to poverty reduction.

The multiple paths to regional capability deprivation support the current agenda to achieve regional integration and greater equality in socioeconomic development. Poverty in Colombia has several causes, one of which is forced displacement due to the internal conflict. The results of fsQCA not only provide guidance for monitoring regional conditions that lead to poverty but also highlight the value of synergies gained from combining different strategies. Specifically, more equitable access to means and capacities should be combined with conditions that contribute to productivity (Mesa de negociaciones 2013). This process must be accompanied by transparent institutions and 
sound governance that is capable of implementing policies to support the economic and social reconstruction necessary to achieve lasting peace (Flores and Nooruddin 2008, 22). Economic growth on its own is not sufficient to alleviate poverty; peace and confidence in Colombia's institutions are of the utmost importance to make combined strategies work.

The fsQCA approach described in this study is useful to identify critical regional conditions, particularly with small samples. Consequently, the present study contributes to the academic debate. It also provides opportunities for future research. This research has certain limitations due to the lack of data for some Colombian departments. It should also be noted that the study was static in nature. In addition, new variables could supplement those that were used in this study. Finally, incorporating case studies would offer a broader understanding of the phenomenon by providing background on the multidimensional patterns explored herein. 


\section{References}

Acemoglu, D., and J. A. Robinson. 2012. "Why Nations Fail: The Origins of Power, Prosperity, and Poverty.” Asean Economic Bulletin 29 (2): 168. Institute of Southeast Asian Studies. doi:10.1355/ae29-2j.

Akanbi, O. A. 2014. "Structural and Institutional Determinants of Poverty in SubSaharan African Countries". Journal of Human Development and Capabilities 16 (1): 122-141. Informa UK Limited. doi:10.1080/19452829.2014.985197.

Ali, A. M. 2010. "In Colombia, it is all About Institutions." Revista Civilizar de Empresa y Economía 1 (1): 23. Universidad Sergio Arboleda. doi:10.22518/2462909x.54.

Alkire, S., and S. Deneulin. 2009. "The human development and capability approach." In An Introduction to the Human Development and Capability Approach, edited by S. Deneulin and L. Shahani, 22-48. London: Earthscan.

Alkire, S., and M. E. Santos. 2013. “A Multidimensional Approach: Poverty Measurement \& Beyond.” Social Indicators Research 112 (2): 239-257. Springer Nature. doi:10.1007/s11205-013-0257-3.

Amin, A. (1999), 'An institutionalist perspective on regional economic development', International Journal of Urban and Regional Research, Vol. 23, pp. 365-378.

Anand S., and A.K. Sen. 1997. Concepts of human development and poverty: a multidimensional perspective. Human Development Papers. New York: United Nations Development Programme (UNDP).

Angulo, R., Y. Díaz, and R. Pardo. 2016. “The Colombian Multidimensional Poverty Index: Measuring Poverty in a Public Policy Context.” Social Indicators Research 127 (1): 1-38. doi:10.1007/s11205-015-0964-z. 
Atkinson, A. B., and F. Bourguignon. "The Comparison of Multi-Dimensioned Distributions of Economic Status". The Review of Economic Studies 49(2):183. doi:10.2307/2297269.

Awan, M. S., N. Malik, H. Sarwar, and M. Waqas. 2011. "Impact of Education on Poverty Reduction.” International Journal of Academic Research 3 (1): 659664.

Banks, C. M., and J. A. Sokolowski. 2009. "From War on Drugs to War against Terrorism: Modeling the evolution of Colombia's counter-insurgency." Social Science Research 38 (1): 146-154. Elsevier BV. doi:10.1016/j.ssresearch.2008.08.001.

Bara, C. 2014. "Incentives and opportunities.” Journal of Peace Research 51 (6): 696710. SAGE Publications. doi:10.1177/0022343314534458.

Barro, R. J. 1991. "Economic Growth in a Cross Section of Countries.” The Quarterly Journal of Economics 106 (2): 407. Oxford University Press (OUP). doi: $10.2307 / 2937943$.

Bastiaensen, J., T. De Herdt, and B. D’Exelle. 2005. "Poverty reduction as a local institutional process." World Development 33 (6): 979-993. Elsevier BV. doi:10.1016/j.worlddev.2004.09.019.

Belhadj, B., and M. Limam. 2012. "Unidimensional and multidimensional fuzzy poverty measures: New approach.” Economic Modelling 29 (4): 995-1002. Elsevier BV. doi:10.1016/j.econmod.2012.03.009.

Belhadj, B. 2011. "New fuzzy indices of poverty by distinguishing three levels of poverty." Research in Economics 65 (3): 221-231. Elsevier BV. doi:10.1016/j.rie.2010.10.002. 
Benmelech, E., C. Berrebi, and E. F. Klor. 2012. "Economic Conditions and the Quality of Suicide Terrorism.” The Journal of Politics 74 (1): 113-128. University of Chicago Press. doi:10.1017/s0022381611001101.

Betti, G., F. Gagliardi, A. Lemmi, and V. Verma. 2011. "Subnational Indicators of Poverty and Deprivation In Europe: Methodology And Applications". Cambridge Journal of Regions, Economy and Society 5(1):129-147. doi:10.1093/cjres/rsr037.

Blomberg, S. B., and G. D. Hess. 2002. "The Temporal Links between Conflict and Economic Activity.” Journal of Conflict Resolution 46 (1): 74-90. SAGE Publications. doi:10.1177/0022002702046001005.

Bourguignon, F., and S. R. Chakravarty. 2003. "The measurement of multidimensional poverty." The Journal of Economic Inequality 1(1): 25-49. doi:10.1023/A:1023913831

Bretthauer, J. M. 2014. “Conditions for Peace and Conflict.” Journal of Conflict Resolution 59 (4): 593-616. SAGE Publications. doi:10.1177/0022002713516841.

Camacho, A., and C. Rodríguez. 2012. "Firm Exit and Armed Conflict in Colombia." Journal of Conflict Resolution 57 (1): 89-116. SAGE Publications. doi:10.1177/0022002712464848.

Caruso, R., and F. Schneider. 2011. "The socio-economic determinants of terrorism and political violence in Western Europe (1994-2007).” European Journal of Political Economy 27: S37-S49. Elsevier BV. doi:10.1016/j.ejpoleco.2011.02.003.

Cerioli A. and S. Zani. 1990. "A fuzzy approach to the measurement of poverty”. In Income and wealth distribution, inequality and poverty. Berlin: Springer Verlag. 
Cervantes-Godoy, D., and J. Dewbre. 2010. "Economic Importance of Agriculture for Poverty Reduction." OECD Food, Agriculture and Fisheries Papers (23). OECD Publishing. doi:10.1787/5kmmv9s20944-en

Charlton, A., and J. Stiglitz. 2004. "Capital Market Liberalization and Poverty." Initiative for Policy Dialogue Working Papers, 1-22.

Collier, D. 1993. “Comparative Method.” In Political Science: The State of Discipline II, edited by A. Finifter, 105-119. Washington D.C.: American Political Science Association.

Constitution of Colombia. 1991. “Constitución Politica de Colombia”. Bogotá: Layer. Corporación Transparencia por Colombia. 2005. "Índice de Transparencia”. [Data file]. DANE. 2018. "Indicadores demográficos.” [Data file]. Retrieved from http://www.dane.gov.co/index.php/estadisticas-por-tema/demografia-ypoblacion/series-de-poblacion

DANE. 2015a. “Cuentas Nacionales Departamemtales.” [Data file]. Retrieved from http://www.dane.gov.co/index.php/cuentas-economicas/cuentas-departamentales

DANE. 2015b. "Demografía.” [Data file]. Retrieved from http://www.dane.gov.co/index.php/poblacion-y-demografia/series-de-poblacion DANE. 2015c. "Población." [Data file]. Retrieved from https://www.dane.gov.co/index.php/estadisticas-por-tema/demografia-ypoblacion/proyecciones-de-poblacion

DANE. 2015d. "Pobreza.” [Data file]. Retrieved from: http://www.dane.gov.co/files/noticias/Pobreza_nuevametodologia.pdf Deaton, A. 2010. "Price Indexes, Inequality, and the Measurement of World Poverty." American Economic Review 100 (1): 5-34. American Economic Association. doi:10.1257/aer.100.1.5. 
Ele-Ojo Ataguba, J., H. Eme Ichoku, and W. M. Fonta. 2013. "Multidimensional poverty assessment: applying the capability approach.” International Journal of Social Economics 40 (4): 331-354. Emerald. doi:10.1108/03068291311305017.

Fiss, P. 2011. "Building Better Causal Theories: A Fuzzy Set Approach to Typologies in Organization Research.” Academy of Management Journal 54 (2): 393-420. The Academy of Management. doi:10.5465/amj.2011.60263120.

Flores, T. E. 2014. "Vertical Inequality, Land Reform, and Insurgency in Colombia". Peace Economics, Peace Science, and Public Policy 20 (1): 5-31. Walter de Gruyter GmbH. doi:10.1515/peps-2013-0058.

Flores, T. E., and I. Nooruddin. 2008. "Democracy under the Gun Understanding Postconflict Economic Recovery.” Journal of Conflict Resolution 53 (1): 3-29. SAGE Publications. doi:10.1177/0022002708326745.

Fosu, A. 2011. "Growth, Inequality, and Poverty Reduction in Developing Countries: Recent Global Evidence”. SSRN Electronic Journal. Elsevier BV. doi:10.2139/ssrn.1813968.

Glick, R., and A. M. Taylor. 2010. "Collateral Damage: Trade Disruption and the Economic Impact of War." Review of Economics and Statistics 92 (1): 102-127. MIT Press - Journals. doi:10.1162/rest.2009.12023.

Harriss, J. 2007. “Bringing politics back into poverty analysis: Why understanding social relations matters more for policy on chronic poverty than measurement". University of Manchester: CPRC Working Paper, 77.

Hegre, H., and H. M. Nygård. 2014. “Governance and Conflict Relapse.” Journal of Conflict Resolution 59 (6): 984-1016. SAGE Publications. doi:10.1177/0022002713520591. 
Hegre, H., J. R. Oneal, and B. Russett. 2010. “Trade does promote peace: New simultaneous estimates of the reciprocal effects of trade and conflict." Journal of Peace Research 47 (6): 763-774. SAGE Publications.

doi:10.1177/0022343310385995.

Hegre, H., G. Østby, and C. Raleigh. 2009. “Poverty and Civil War Events.” Journal of Conflict Resolution 53 (4): 598-623. SAGE Publications. doi:10.1177/0022002709336459.

Husseima, G., and J. B. Rejeb. 2012. "Poverty, Growth, and Inequality in Developing Countries.” International Journal of Economics and Financial Issues 2 (4): 470479. ISSN: 2146-4138.

Iniguez-Montiel, A. J. 2014. "Growth with Equity for the Development of Mexico: Poverty, Inequality, and Economic Growth (1992-2008).” World Development 59: 313-326. Elsevier BV. doi:10.1016/j.worlddev.2014.01.011.

Justino, P. 2009. "Poverty and Violent Conflict: A Micro-Level Perspective on the Causes and Duration of Warfare.” Journal of Peace Research 46 (3): 315-333. SAGE Publications. doi:10.1177/0022343309102655.

Kolm S.C. 1977. Multidimensional egalitarism. Quarterly Journal of Economics 91(1): 1-13. doi: $10.2307 / 1883135$.

Krugman, P. 1997. Development, Geography and Economic Theory. Cambridge: MIT Press.

Lee, A. 2011. "Who Becomes a Terrorist? Poverty, Education, and the Origins of Political Violence.” World Politics 63 (2): 203-245. Cambridge University Press (CUP). doi:10.1017/s0043887111000013.

Lemmi, A., and B. Gianni. 2006. Fuzzy Set Approach to Multidimensional Poverty Measurement. [New York]: Springer. 
March, J. G., and J. P. Olsen. 1989. Rediscovering institutions. Enskede: TPB.

Massey, D. B. 1995. Spatial Divisions of Labour: Social Structures and the Geography of Production. Basingstoke: Macmillan.

Mesa de Conversaciones. 2013. "Primer Informe Conjunto de la Mesa de Conversaciones entre el Gobierno de la República de Colombia y las Fuerzas Armadas Revolucionarias de Colombia-Ejército del Pueblo.” La Habana: 1-13.

Meyer, A. D., A. S. Tsui, and C. R. Hinings. 1993. “Configurational Approaches To Organizational Analysis.” Academy Of Management Journal 36 (6): 1175-1195. doi:10.5465/256809.

Ministry of Education. 2015. "Tuition 2002 certified by the Ministries of Education; 2003 - 2012.” MEN Integrated Registration System, SIMAT.

Misangyi, V. F., and A. G. Acharya. 2014. "Substitutes or Complements? A Configurational Examination of Corporate Governance Mechanisms.” Academy of Management Journal 57 (6): 1681-1705. The Academy of Management. doi:10.5465/amj.2012.0728.

Misangyi, V. F., T. Greckhamer, S. Furnari, P. C. Fiss, D. Crilly, and R. Aguilera. 2017. “Embracing Causal Complexity.” Journal of Management 43 (1): 255-282. doi:10.1177/0149206316679252.

Müller, T. R. 2011. "Introduction to human resource development versus the right to education: Reflections on the paradoxes of education policy making." Journal of International Development 23 (2): 253-261. Wiley-Blackwell. doi:10.1002/jid.1768.

Mwangi, E., and H. Markelova. 2009. “Collective Action and Property Rights for Poverty Reduction: A Review of Methods and Approaches.” Development 
Policy Review 27 (3): 307-331. Wiley-Blackwell. doi:10.1111/j.1467-

7679.2009.00448.x.

Neff, D. 2013. "Fuzzy set-theoretic applications in poverty research.” Policy and Society 32 (4): 319-331. Informa UK Limited. doi:10.1016/j.polsoc.2013.10.004.

North, D. C. 1991. “Institutions.” Journal of Economic Institutions 5 (1): 97-117.

North, D. C. 1993. Institutions, institutional change and economic performance. Cambridg, UK: Cambridge University Press

Piazza, J. A. 2011. "Poverty, minority economic discrimination, and domestic terrorism.” Journal of Peace Research 48 (3): 339-353. SAGE Publications. doi:10.1177/0022343310397404.

Powell, W. W., and P. J. DiMaggio, ed. 1991. The New Institutionalism in Organizational Analysis. Chicago and London: University of Chicago Press.

Ragin, C., and P. Fiss. 2008. "Net Effects Analysis versus Configurational Analysis: An Empirical Demonstration.” In Redesigning social inquiry: Fuzzy sets and beyond, edited by C. Ragin, 190-212. Chicago: University of Chicago Press.

Ragin, C. C. 2008. Redesigning Social Inquiry: Fuzzy Sets and Beyond. Chicago: University of Chicago Press.

Rihoux, B., and C. Ragin. 2009. Configurational comparative methods: Qualitative comparative analysis (QCA), and related techniques. Thousand Oaks, CA: SAGE Publications.

Rodrik, D. (2005). “Políticas de diversificación económica.” Revista de la CEPAL 87: $7-23$.

Rodrik, D. 2006. “Goodbye Washington Consensus, Hello Washington Confusion? A Review of the World Bank's Economic Growth in the 1990s: Learning from a 
Decade of Reform.” Journal of Economic Literature 44 (4): 973-987. American Economic Association. doi:10.1257/jel.44.4.973.

Royuela, V., and G. A. García. 2015. "Economic And Social Convergence In Colombia.” Regional Studies 49 (2): 219-239. doi:10.1080/00343404.2012.762086.

Schneider, C. Q., and C. Wagemann. 2010. "Standards of Good Practice in Qualitative Comparative Analysis (QCA) and Fuzzy-Sets.” Comparative Sociology 9 (3): 397-418. Brill Academic Publishers. doi:10.1163/156913210x12493538729793.

Schneider, M. R, C. Schulze-Bentrop, and M. Paunescu. 2010. "Mapping the institutional capital of high-tech firms: A fuzzy-set analysis of capitalist variety and export performance.” Journal of International Business Studies 41 (2): 246266. Springer Nature. doi:10.1057/jibs.2009.36.

Sen, A. 2001. Development as freedom. Oxford Paperbacks.

Smeeding T., P. Saunders, J. Coder, S.P. Jenkins, J. Fritzell, A. Hagenaars, R. Hauser . and M. Wolfson. 1993. "Poverty, tnequaltty, and famtly living standards impacts across seven nations: the effect of noncash subsidies for health, education and housing". Review of Income and Wealth 39(3): 229-256. doi:10.1111/j.14754991.1993.tb00458.x.

Solow, R. M. 1957. "Technical Change and the Aggregate Production Function.” The Review of Economics and Statistics 39 (3): 312-320. JSTOR. doi:10.2307/1926047.

Soriano, B., and A. Garrido. 2015. "The role of private sector in development: The relation between public-private investment in infrastructure and agricultural exports in developing countries." Economía Agraria y Recursos Naturales 15 
(2): 93-117. Asociación Española de Economía Agraria.

doi:10.7201/earn.2015.02.05.

Streeten, P. 1994. "Human development: means and ends". The American Economic Review 84 (2): 232-237.

Strezov, V., A. Evans, and T. J. Evans. 2017. “Assessment of the Economic, Social and Environmental Dimensions of the Indicators for Sustainable

Development.” Sustainable Development 25 (3): 242-253. doi:10.1002/sd.1649.

Tebaldi, E., and R. Mohan. 2010. "Institutions and Poverty.” Journal of Development Studies 46 (6): 1047-1066. Informa UK Limited. doi:10.1080/00220380903012730.

Thelen, K. 2004. How Institutions Evolve: The Political Economy of Skills in Germany, Britain, the United States, and Japan. Cambridge, UK: Cambridge University Press.

Tsui, K.Y. "Multidimensional Generalizations of The Relative and Absolute Inequality Indices: The Atkinson-Kolm-Sen Approach".1995. Journal of Economic Theory 67(1): 251-265. doi:10.1006/jeth.1995.1073.

Transparencia por Colombia. 2015. Índice de Transparencia Departamental. [Data file]. Retrieved from: http://transparenciacolombia.org.co UNPD 2015. Human Developmen Report. Work for Human Development, Retrieved from: http://report.hdr.undp.org

Vis, B. 2012. "The Comparative Advantages of fsQCA and Regression Analysis for Moderately Large-N Analyses.” Sociological Methods \& Research 41 (1): 168198. SAGE Publications. doi:10.1177/0049124112442142.

World Bank. 2009. Reshaping economic geography. Washington: The World Bank. 